\title{
Kultische Sprache in den Paulusbriefen
}

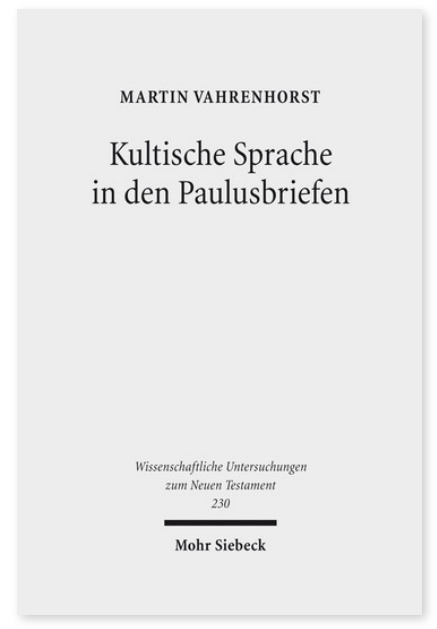

2008. XI, 420 Seiten. WUNT I 230

ISBN 978-3-16-151519-4

DOI 10.1628/978-3-16-151519-4

eBook PDF 139,00 €

ISBN 978-3-16-149714-8

Leinen $139,00 €$
Die paulinischen Briefe sind durchzogen von Passagen, in denen Paulus sich einer Sprache bedient, die kultisch konnotiert ist. Paulus teilt den Adressaten seiner Briefe in kultisch geprägter Sprache wesentliches über ihr Verhältnis zu Gott, den sich daraus ergebenden ethischen Konsequenzen, den Transfer auf die Seite Gottes und die Rolle des Apostels in diesem Prozess mit.

Die Untersuchung paganer und jüdischer Kultzusammenhänge lässt große Gemeinsamkeiten zwischen den Kultvollzügen Israels und denen paganer Kulte erkennen, die in dieser Studie vor allem anhand der Leges Sacrae in den Blick genommen werden. So erweist sich die heute fremde Sprache des Kultes als gemeinsame Basis, auf der sich Paulus und seine nichtjüdischen Adressaten begegnen und verstehen konnten.

Martin Vahrenhorst untersucht die religionsgeschichtlichen Kontexte und die kultisch geprägten Passagen in den gemeinhin für paulinisch gehaltenen Briefen. Aus dem beschriebenen Rahmen fällt allein der Galaterbrief heraus. Hier greift Paulus anstelle der kultischen Sprache verstärkt auf das Wortfeld Gerechtigkeit zurück, das schon in früheren Briefen gelegentlich parallel zur kultischen Begrifflichkeit verwendet wird. Eignete sich dieses Wortfeld besser zur Auseinandersetzung mit den Gegnern des Paulus, die gerade um der Heiligkeit willen den Übertritt zum Judentum propagieren konnten?

Kontinuitäten und Entwicklungen im paulinischen Denken können anhand der Untersuchung der kultischen Sprache in den Paulusbriefen in besonderer Weise sichtbar werden.

Martin Vahrenhorst Geboren 1967; 2002 Promotion; seit 2007 koordiniert er die Bildungsarbeit der EKD in Jerusalem; er leitet das Studienprogramm »Studium in Israel« und ist Mitarbeiter am »Deutschen Evangelischen Institut« in Jerusalem.

\section{Jetzt bestellen:}

https://mohrsiebeck.com/buch/kultische-sprache-in-den-paulusbriefen-9783161515194?no_cache=1

order@mohrsiebeck.com

Telefon: +49 (0)7071-923-17

Telefax: $+49(0) 7071-51104$ 